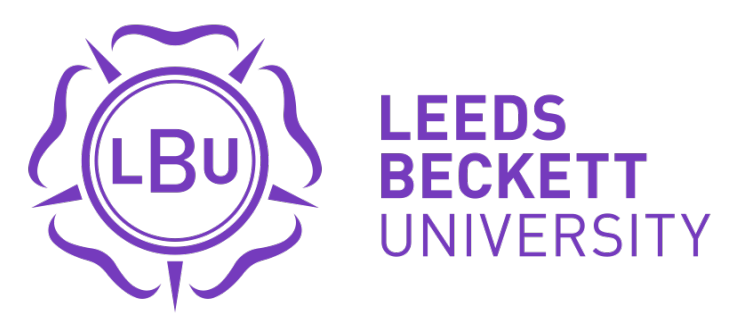

Citation:

Tee, JC and Coopoo, Y and Lambert, M (2019) Pacing characteristics of whole and part-game players in professional rugby union. European Journal of Sport Science. ISSN 1536-7290 DOI: https://doi.org/10.1080/17461391.2019.1660410

Link to Leeds Beckett Repository record:

https://eprints.leedsbeckett.ac.uk/id/eprint/6122/

Document Version:

Article (Accepted Version)

This is an Accepted Manuscript of an article published by Taylor \& Francis in European Journal of Sport Science on 10 Sep 2019, available online: http://www.tandfonline.com/10.1080/17461391.2019.1660410

The aim of the Leeds Beckett Repository is to provide open access to our research, as required by funder policies and permitted by publishers and copyright law.

The Leeds Beckett repository holds a wide range of publications, each of which has been checked for copyright and the relevant embargo period has been applied by the Research Services team.

We operate on a standard take-down policy. If you are the author or publisher of an output and you would like it removed from the repository, please contact us and we will investigate on a case-by-case basis.

Each thesis in the repository has been cleared where necessary by the author for third party copyright. If you would like a thesis to be removed from the repository or believe there is an issue with copyright, please contact us on openaccess@leedsbeckett.ac.uk and we will investigate on a case-by-case basis. 
Pacing characteristics of whole and part-game players in professional rugby union

Jason C. Tee ${ }^{\mathrm{a}, \mathrm{b}}$, Yoga Coopoo $^{\mathrm{c}}$ and Mike Lambert ${ }^{\mathrm{d}}$

${ }^{a}$ : Institute for Sport, Physical Activity and Leisure, Leeds Beckett University, Leeds, West Yorkshire, United Kingdom

${ }^{b}$ : Department of Sport Studies, Faculty of Applied Sciences, Durban University of Technology, South Africa.

${ }^{c}$ : Department of Sport and Movement Studies, Faculty of Health Sciences, University of Johannesburg, Johannesburg, South Africa

${ }^{d}$ : Division of Exercise Science and Sports Medicine, Faculty of Health Sciences, University of Cape Town, South Africa.

Corresponding Author

Jason Cameron Tee,

Department of Sport Studies,

Faculty of Applied Sciences,

Durban University of Technology,

South Africa

Email: jasonctee@gmail.com 


\section{Pacing characteristics of whole and part-game players in professional rugby union}

Contemporary theories on players' intensity distribution in team sports suggest that they regulate their outputs using pacing strategies. There is currently limited information on how movement patterns and pacing strategies of rugby union players in different position groups (forwards and backs) vary when exposed to different bout types (whole game, starter or finisher). Global positioning system (GPS) and accelerometer data were collected from 100 professional match participations to determine temporal effects on movement patterns. For forwards, finishers (players who entered the game as substitutes) demonstrated significantly greater high-speed running distance $(\%$ difference, $\pm 90 \% \mathrm{CI}$; magnitude based inference and effect size) ( $\uparrow 55, \pm 17 \%$; very likely large) and acceleration frequency ( $\uparrow 78, \pm 59 \%$; very likely large) than whole game players. For backs, starters (players who started the game and were later substituted) displayed greater high speed running distance than whole game players $(+27, \pm 21 \%$; ES = likely medium) but this difference did not achieve statistical significance $(p=0.07)$. Forwards displayed "slow-positive" pacing strategies regardless of bout type, while backs displayed "flat" pacing strategies. Forwards and backs adopt different pacing strategies regardless of bout type, with forwards demonstrating progressively greater performance decrements over the course of the match. These findings reflect differing physical demands, notably contact and running loads, of players in different positions. .

Keywords: Pacing; team sport; intensity; temporal; GPS 


\section{Introduction}

Rugby union match play is defined by physical contests for possession that precede every phase of play (Tee, Ashford \& Piggott, 2018). As such movement patterns consist of repetitive bouts of short duration maximal effort activity (accelerating, sprinting, tackles and collisions), interspersed with periods of lowintensity activity (standing, walking and jogging) (Austin, Gabbett, \& Jenkins, 2011; Lindsay, Draper, Lewis, Gieseg, \& Gill, 2015). Positions are broadly defined as backs and forwards with forwards responsible for competing for possession and backs for executing tactical plays to use that possession (Duthie, Pyne \& Hooper, 2003). These differing roles result in different physical demands, with forwards being involved in more total impacts, tackles and rucks and backs experiencing greater total and highspeed running demands (Lindsay et al., 2015, Jones et al., 2015, Tee \& Coopoo, 2015).

Rugby union participation results in post-match fatigue that can be observed through reduced neuromuscular function, hormonal and mood disturbances (West et al., 2013), and metabolic substrate depletion (Bradley et al., 2016). Despite this clear evidence of fatigue, analysis of movement patterns during match play shows that physical performance outputs (e.g. meters per minute) are generally maintained over the duration of the match (Lacome, Piscione, Hager, \& Bourdin, 2013; Roberts, Trewartha, Higgitt, El-Abd, and Stokes, 2008; Jones et. al., 2015; Tee, Lambert, \& Coopoo, 2016), and that 'catastrophic' fatigue (St Clair-Gibson and Noakes, 2004) rarely occurs. Further, rugby players maintain their ability to engage in these transient high intensity bouts throughout the match (Jones et al., 2015;). This suggests that players pace themselves to maintain physical performance over the duration of the match. 
Pacing is defined as "The goal directed distribution and management of effort across the duration of an exercise bout" (Edwards and Polman, 2012). Contemporary pacing theory suggests that pacing takes place via teleoanticipatory mechanisms (Ulmer, 1996). Prior to participation, players construct a 'macro-pacing' strategy based on knowledge of the bout duration, motivation, opposition, environmental and metabolic conditions (Edwards and Noakes, 2009; Waldron \& Highton, 2014). During the playing period, information regarding the degree of physical exertion that the body is being exposed to is communicated to the brain (Waldron \& Highton, 2014), and compared against psychological drive (e.g. level of motivation) (St ClairGibson et al., 2013), and pacing decisions emerge from the balance between competing requirements of physiological protective and psychological success-related drives (St Clair-Gibson et al., 2018). When physiological distress exceeds what the participant is willing to tolerate based on their level of motivation, physical outputs are down regulated (St Clair-Gibson et al., 2018; Edwards and Noakes, 2009; Waldron \& Highton, 2014). Physical stress and psychological drive vary throughout the game causing physical to oscillate throughout the playing bout (St Clair-Gibson et al., 2018). As examples of this phenomenon, team sport players are known to reduce activity levels for brief periods following high-intensity activity bouts (Bradley \& Noakes, 2013; Waldron, Highton, Daniels, \& Twist, 2013), but also vary physical outputs in response to match score (Black \& Gabbett, 2014).

Pacing theory predicts that knowledge of bout duration will have a meaningful effect on physical performance with greater physical outputs possible during shorter exercise periods (Gabbett, Walker, \& Walker, 2015; Highton, Mullen, \& Twist, 2017; Sampson, Fullagar, \& Gabbett, 2015). In team sports, this effect is particularly relevant to substitute and interchange players. Increased physical performance has 
been demonstrated by substitute players in soccer (Carling, Espié, Le Gall, Bloomfield, \& Jullien, 2010), rugby league (Waldron et al., 2013), rugby sevens (Higham, Pyne, Anson, \& Eddy, 2011; Murray \& Varley, 2015) and rugby union (Lacome, et al., 2015). The influence of substitutes on match intensity could influence match outcomes because winning teams display increased physical performance in comparison to losing teams (Gabbett, 2013; Black \& Gabbett, 2014, Hulin, Gabbett, Kearney and Corvo, 2015).

It should be noted that the physical performance of team sport players is affected by factors beyond pacing and fatigue phenomena. Movement patterns are affected by contextual factors such as how the opposition 'allow' a team to play (Gréhaigne \& Godbout, 2014; Gabbett, 2013), ball in play time (Gabbett, 2015) and attacking and defensive involvements (Kempton and Coutts, 2015). These contextual interactions induce a high level of variability to the assessment of physical performances during game play (McLaren, et al., 2015), which must be acknowledged when assessing pacing effects.

It has been proposed that in collision sports like rugby union, the potential mismatch between "fresh" substitutes and "fatigued" whole game players may be a risk factor for injury (Orchard, 2012). In rugby union a total of eight substitutes may be used $(>50 \%$ of the starting team can be substituted) increasing the potential for substitute players to affect overall match intensity. Previous rugby union research has demonstrated that substitute players show small to moderate improvements in running performance vs. the players they replaced (Lacome et al., 2015), but did not examine acceleration or impact characteristics, which may be subject to larger effects due to the collision demands of the game. Further, substitutes adopt a "one bout-all out" pacing strategy (Waldron \& Highton, 2014), where they start playing at a high level 
of physical performance, but reduce these performance outputs rapidly. Therefore, it is important to describe the pacing profile of substitute players to better understand the timeframe for which they may be able to outperform whole game players.

The aim of this research was to examine the pacing profiles of rugby union players who participated in the whole game, starter players (players who start the match and are later substituted) and finisher players (players who do not start the game and come on as substitutes) by position (forwards or backs). This will provide novel information on the magnitude and time course differences in physical performance between whole game and part-game players. This information may be useful for coaches attempting to maximize the impact of their substitutes on tactical and performance match play outcomes.

\section{Materials and methods}

A prospective, observational design was used to assess the pacing strategies of professional rugby players based on whether they completed the entire game (whole), started the game but were substituted (starters), or came on as substitutes (finishers).

\section{Participants}

Nineteen rugby union players (age $26 \pm 2$ years; body mass $101.5 \pm 12.2 \mathrm{~kg}$, stature $1.86 \pm 0.07 \mathrm{~m}$, playing experience $47 \pm 44$ professional games) were recruited from within a South African professional team and consented to participate in this research study. The team played at the highest level of domestic competition in South Africa, competing in both the Vodacom Cup and Currie Cup competitions. They provided a total of 103 GPS and accelerometer data files from 23 different matches in the 2013 rugby season. The study was approved by the University of Johannesburg 
Ethical Review Committee and followed the code of ethics of the World Medical Association (Declaration of Helsinki).

\section{Procedure}

Participants wore SPI Pro GPS and accelerometer devices (GPSports, Canberra, Australia) while participating in professional matches in the 2013 rugby season. The devices were supported between the shoulder blades by an elasticated harness worn underneath the playing jersey. The GPS receiver sampled at a frequency of $10 \mathrm{~Hz}$, and contained an integrated triaxial accelerometer sampling at $100 \mathrm{~Hz}$. The accelerometer calculates instantaneous player collision-forces by calculating the sum of gravitational acceleration forces in three axes $(x, y$ and $z)$. The reliability of both the GPS (Coutts \& Duffield, 2010) and accelerometer (Kelly, Murphy, Watsford, Austin, \& Rennie, 2015) devices has been shown to be acceptable for the assessment of movement variables in team sports.

Players were familiarized with the use of the GPS and accelerometer units at practice sessions before using them in matches. Units were switched on before the warm up, typically 45 minutes before kick-off, to ensure adequate time to establish satellite signal. During matches, data were recorded regarding player substitutions to facilitate the assessment of bout type effects. In cases where substitutions occurred as a result of injury ( 2 occasions) or yellow card/blood bin ( 1 occasion) these data were excluded from the final data set because the playing bout would not reflect prior knowledge of the expected bout duration. All substitutions were like for like in terms of position (e.g. scrumhalf replacing scrumhalf).

Following matches, data were downloaded and cleaned using Team AMS software (Version 10, GPSports ${ }^{\mathrm{TM}}$, Canberra, Australia). All non-playing time including warm up, half time and periods when players were not on the field due to 
substitution were excluded from the match file so that only actual playing time remained. Each data file was grouped according to position (forward or back) and bout type (whole, starter or finisher). To allow for the interpretation of pacing profiles, data for each playing bout were split into even quartiles.

\section{GPS and Accelerometer variables}

Playing time was calculated as the total duration time the player spent on the field of play, including stoppage time for injuries or video referee decisions. Therefore, actual playing times exceeded the stipulated 80 minute match duration. Due to differences in total playing time between bout type (whole, starter or finisher), all data were normalised to playing time to allow for reasonable comparison. As such, data relating to relative distance $\left(\mathrm{m} \bullet \mathrm{min}^{-1}\right)$, high speed distance $\left(\mathrm{m} \cdot \mathrm{min}^{-1}>4 \mathrm{~m} \bullet \mathrm{s}^{-1}\right)$, acceleration frequency (accelerations $>2.75 \mathrm{~m} \bullet \mathrm{s}^{-1}$ per minute) and accelerometer derived impact frequency (impacts $>5 \mathrm{G}$ per minute) were recorded as the variables of interest (Tee et al., 2016). Relative distance provides a broad assessment of the total work rate displayed by individual players and is the most commonly reported metric in GPS research (Cummins et al., 2013). Additional metrics were selected to provide further detail regarding specific physiological challenges. The high speed distance metric reflects distance run where there is a significant contribution from the anaerobic energy system (Scott and Lovell, 2017). Acceleration frequency was included because accelerating is a physiologically taxing activity, but may occur at lower velocities and thus not be reflected in the high speed running metric (Delaney, Cummins, Thornton \& Duthie, 2018). Finally, GPS measures are unable to quantify many physiologically demanding activities that occur in rugby such as wrestling, tackling and collisions. The impact frequency measure was included in an attempt to quantify these demands. Impact frequency records a broad range of impacts ranging 
from light impacts caused by heavy foot strikes during a rapid acceleration, deceleration, or change of direction to a severe collision with opposition players (Cunniffe et al., 2009). Impact measures have previously been correlated with increased muscle damage (McLellan, Lovell and Gass, 2011) and reduced neuromuscular function (McLellan and Lovell, 2012) following sports participation. Previous research has demonstrated the sensitivity of these metrics to pacing/fatigue effects in team sport (Aughey 2010; Black \& Gabbett, 2014; Murray \& Varley, 2015; Tee et al., 2016).

\section{Statistical Analysis}

Throughout the results, group mean data are reported as mean \pm SD. Statistical analyses were performed using $\mathrm{R}$ (version 3.5.3). Linear mixed effects models were created using the Ime4 package (Bates, Maechler, Bolker and Walker, 2019) and used to estimate differences in player performance according to bout type, and subsequently according to bout quartile. In all models player identity and match identity were included as random effects. Differences as a result of bout type were examined by including bout type (whole game, starter, finisher) as a fixed effect within the model. Subsequently, temporal changes in movement patterns within bouts were examined by including quartile $(1,2,3,4)$ as a fixed effect within the model. Where significant effects $(\mathrm{p}<0.05)$ of bout or quartile were observed, post hoc pairwise comparisons were conducted by calculating the differences between the least squares means using the emmeans package (Lenth, 2019).

All pairwise comparisons were analysed by calculating effect sizes with $90 \%$ confidence limits. The magnitude of effects were rated as trivial $(<0.2)$, small $(0.20-$ 0.59), medium (0.60-1.19), large (1.20-1.99) or very large (>2.0) (Hopkins, Marshall, 
Batterham, \& Hanin, 2009). Difference between groups or time points are reported as effect size $\pm 90 \% \mathrm{CI}$ or as $\%$ difference/change, $\pm 90 \% \mathrm{Cl}$ as appropriate.

This analysis was further supported through the use of magnitude-based decisions (MBDs) to estimate the practical relevance of the outcomes. This approach is consistent with previous analysis of pacing effects in team sports (Tee et al., 2017; Murray and Varley, 2015). MBD's were derived using $p$ values from the least squares means tests of the linear mixed effects model. The smallest practically meaningful effect was considered to be $0.2 \mathrm{x}$ the between subject standard deviation of the measure, based on Cohen's $d$ effect size (ES) principle. Effects were deemed unclear if their confidence intervals overlapped both the thresholds for substantiveness, meaning that the effect could be substantially positive and negative. Qualitative descriptors are used to describe the likelihood that the true magnitude of the effect is substantial according to the following schema: $<0.5 \%$, most unlikely; $0.5-5 \%$, very unlikely; 5-25\%, unlikely; 25-75\%, possibly; 75-95\%, likely; 95-99.5\%, very likely; $>99.5 \%$, most likely.

To assess the level of disparity in physical outputs induced by finishers, all four quartiles of the finishers playing bout were compared with the final quartile for whole game players (as these periods typically overlap during match play). Similarly, a comparison was conducted between finishers and with the final quartile played by starters. This analysis was only performed for forwards, because only three finisher involvements were recorded for backs. 


\section{Results}

\section{Differences in locomotive variables according to bout type}

Table 1 presents the differences in locomotive variables for forwards and backs according to the bout type completed - whole, starter or finisher. For forwards, bout type had a significant effect on high speed distance $(p=0.007)$, acceleration frequency $(p=0.005)$ and impact frequency $(p=0.038)$ with shorter playing bouts resulting in increased physical outputs. Post hoc tests revealed that forward finishers exceeded the high-speed distance and acceleration frequency of whole game players and starters. The magnitude of the difference in physical performance between finishers and whole game players was $55 \pm 17 \%$ for high intensity distance (very likely large), and $78 \pm 59 \%$ for acceleration frequency (very likely large). There was also a likely large $(\uparrow 102, \pm 105 \%)$ difference between whole game players and finishers for impact frequency, yet this did not achieve statistical significance $(p=$ 0.0847).

For backs, there were likely medium differences between whole game players and starters for relative distance $(\uparrow 8, \pm 6 \%$; likely medium) and high speed running distance ( $\uparrow 27, \pm 21 \%$; likely medium). Again, these bout type effects did not reach did statistical significance (relative distance $p=0.237$; high speed running distance $p=$ 0.08). 


\section{Temporal changes in physical performance variables}

Temporal effects were assessed by adding 'quartile' as a fixed effect to the linear mixed model. For forwards, relative distance $(p=0.001)$, high speed running distance $(p=0.001)$ and acceleration frequency $(p=0.005)$ were all subject to significant temporal effects (decreased over time). No significant temporal effects were present for backs. Figure 1 illustrates the changes in physical performance over time for backs and forwards according to bout type. As an example of this phenomenon, collectively forwards experience meaningful reductions in movement intensity from quartile 1 to 4 for relative distance $(\downarrow 9.2, \pm 5.5 \%$; very likely medium), high-intensity distance $(\downarrow 45, \pm 16 \%$; almost certainly large) and acceleration frequency $(\downarrow 5.1, \pm 3.2 \%$; very likely medium). In comparison, backs demonstrate negligible changes in physical performance: relative distance $(\downarrow 4.2, \pm 4.7 \%$; possibly small), high-intensity distance $(\downarrow 8, \pm 15 \%$; possibly trivial) and impact frequency ( $\downarrow$ $16, \pm 14 \%$; likely small). It is also evident that differences in physical performance measures between bout type are fairly consistent over time for backs, but vary greatly for forwards.

*** Figure 1 near here $* * *$

Table 2 presents the paired comparisons for physical performance variables for backs and forwards across quartiles of the respective playing bouts. For forwards, no differences between whole game players and starters were apparent, except for a likely small $(5.5, \pm 8.3 \%)$ difference in relative distance covered in quartile 2.

Finishers demonstrated increased physical performance over whole game players and starters for high speed running distance, acceleration frequency and impact frequency 
in most quartiles (Table 2). No meaningful differences were observed for backs at any timepoint.

*** Table 2 near here $* * *$

\section{The effect of finishers on match intensity}

All four quartiles played by the finishers were compared with the final quartile played by whole game players, and with the final quartile played by starters (Table 3). Finishers exceed the movement intensity of whole game players and starters in all locomotive categories during their first two quartiles of match involvement (small to large effect sizes). This effect on match intensity is reduced in quartile 3 (unclear to small effects). Variable effects were observed in the final quarter where there were no meaningful differences in relative distance and acceleration frequency, but likely to very likely medium differences in high intensity running and impact frequency were present. Figure 2 presents these data as a time series to indicate graphically the difference in playing intensity between whole game players and finishers and how this effect progresses over time.

*** Table 3 and Figure 2 near here $* * *$

\section{Discussion}

The aim of this research was to examine whether the pacing profiles of rugby union players differ when exposed to different bout types and whether these differences are position specific. The main finding of this study was that forward 
finishers exceed the physical outputs of whole game players and starters for highspeed running and acceleration frequency (Table 1). Finisher impact frequency was also subject to likely large effects, although this movement parameter did not achieve statistical significance $(p=0.08)$. For finishers in the backs position, differences from other bout types were unclear likely due to the small sample available for analysis. The findings for forwards agree with previous research showing that when the bout duration is known, participants exert themselves at higher intensities during shorter exercise bouts (Gabbett et al., 2015; Highton et al., 2017; Sampson et al., 2015). Further, these findings agree with results from other sports indicating that substitutes demonstrate higher playing intensities than whole game players (Carling et al., 2010; Higham et al., 2011; Murray \& Varley, 2015; Waldron et al., 2013)

In particular these results agree with those of Lacome et al. (2015) who showed that rugby union substitutes cover more total and high-intensity running distance than both whole game players, and the players they replaced. The Lacome et al. (2015) work also described a number of technical performance measures, but was unable to show clear bout type effects by using these metrics. The current study advances the work of Lacome et al., (2015) in two ways: 1.) by demonstrating larger pacing effects by including measures of acceleration and impact frequency, and 2.) by demonstrating how these effects change over time. Overall, these findings demonstrate that the inserting of forward finishers into the game will have a meaningful effect on game speed. This suggests that forwards who play the whole game need to have very well-developed physical capacities in order to cope with the increased physical performance potential of fresh finisher players who join the game when they are already fatigued. 
An unexpected finding of this study was the lack of demonstrable bout effects between whole game players and starters. For forwards, no clear effects were observed, while for backs there were likely medium effects for relative distance and high speed running distance, but these did not achieve statistical significance. Pacing theory suggests that starters should demonstrate higher levels of physical performance than whole game players because they are subject to shorter playing bouts ( 95 vs 60 mins), but there was no evidence of this. One potential explanation for this phenomenon is that because of the high level of variability (McLaren, et al., 2015) and unpredictablity (Gréhaigne \& Godbout, 2014) inherent in rugby union match play, players cannot 'anticipate' differences in physical exertion with enough confidence to allow them to set a higher pacing strategy. This is similar to how runners self-select a more conservative running pace when they are unaware of the end point of exercise (Baden et al., 2005). An equally plausible explanation is that starters do not trust that they will be substituted at the time expected, and so set a pacing strategy consistent with that of whole game players account for this eventuality. Indeed, even when substitution strategies are explicitly detailed before the game, there is always a risk that an unexpected injury will force a player to remain on the field longer than expected.

It is possible to examine pacing effects more deeply by dividing exercise bouts into smaller sections, (quartiles in this study) to demonstrate how effort is distributed over the time course of the playing bout. The results of this study demonstrated that playing quartile had a significant effect on physical performance in relative distance, high-speed distance and acceleration frequency for forwards, but no effect for backs. These findings are in agreement with previous research in rugby union has established that forwards employ a "slow-positive" (start at a high level of intensity and gradually 
decline through the exercise bout) pacing strategy, while backs seemingly employ a "flat" (maintaining consistent outputs throughout the exercise bout) pacing strategy (Tee et al., 2016). The previous findings of Tee et al., (2016) only examined whole game players. The current study demonstrates that this effect remains present across different bout types.

The difference in pacing strategies between backs and forwards may be explained by differences in contact exposure. In rugby union, forwards are exposed to more contacts and collisions than backs (Austin et al., 2011; Lindsay et al., 2015). Exposure to physical contact has been shown to reduce total (Johnston, Gabbett, Seibold, \& Jenkins, 2014), and high-speed running distance (Johnston, Gabbett, \& Jenkins, 2014) in small-sided games and during peak demand periods of rugby league match play (Johnston, Weaving, Hulin, Till, Jones \& Duthie, 2019). The magnitude of this response is associated with the player's number of contact efforts (Johnston, Gabbett, Walker, Walker and Jenkins, 2014; Johnston, Weaving, Hulin, Till, Jones and Duthie, 2019). It is likely that due to the highly demanding nature of these contact exposures, players progressively reduce their physical outputs over the course of a game to maintain the ability to continue engaging in these high intensity activities. It is possible that because backs are exposed to fewer contacts, they do not need to regulate their activity in this way.

The presence of temporal pacing effects for finisher forwards is important to consider, because if finishers adopt a slow-positive pacing strategy, the physical performance advantage that they demonstrate over whole game players may diminish over time. This is demonstrated by finishers producing higher levels of physical performance than whole game and starter players in the first two quartiles of their involvement, but by the third quartile these differences reduce to small or unclear 
effects (Figure 2). Similar findings have been observed in soccer where substitutes showed reductions in a number of physical performance variables after the first five minutes on the pitch (Hills et al, 2019). It appears that for some physical performance measures, finisher players are able to increase their effort level from quartile 3 to 4 (Table 2), this is consistent with the "end spurt" phenomenon (Waldron \& Highton, 2014). The presence of the "end spurt" suggests that players down regulate their output to ensure that they can complete their playing bout. Once the athlete is assured of reaching the end of the bout he up-regulates his output and expends his energy reserves. It is possible that if the other bout types were examined in greater resolution “end-spurts" would be observed for these too (Waldron \& Highton, 2014). The end spurt could also be explained by increased effort of the players in the final moments of the match if the result is in the balance, or by disengagement by the opponents if the game is clearly won or lost allowing player more freedom of movement.

This research has a number of applied practical applications. Firstly, it suggests that high speed running and acceleration frequency are the best candidate performance measures for measuring pacing effects in rugby union players. These two variables demonstrated significant medium to large effects in this study. It is likely that the utility of the acceleration metric could be improved by employing nondiscretized methods (Delaney et al., 2018), but this was not possible in this study. In contrast, relative distance and impact frequency did not clearly discriminate between bout types. Previously, Lacome et al (2015) did demonstrate meaningful bout effects using the relative distance metric, but the observed effects were small with a much larger sample size. Secondly, this research demonstrates that finisher players can have a meaningful impact on game intensity, but that this advantage is relatively short lived. Therefore, coaches should plan substitution strategies carefully to maximise 
benefit for their team. Finally, this research provides insight into the magnitude and time course of differences in playing intensity that whole game players are exposed to when finishers are inserted into the game. Consideration of this phenomenon may be important when assessing injury risk (Orchard, 2012).

This study was subject to a number of limitations that should be improved upon in future research. It was only possible to collect data on three back finisher involvements, making it difficult to demonstrate effects within this group due to the small sample size. Further, while improved insight was provided by assessing players within forwards and backs positions, these positional groups are still relatively heterogeneous. This research can be improved through the collection of a larger sample that would allow assessment in individual positions. In addition, the analysis of physical performance during ball in play periods and during shorter 'rolling window' periods could provide further insight into this topic. Finally, this research was conducted within a single team and the effects demonstrated here may be particular to the team's own tactical approach. Future research should aim to include multiple teams with different playing styles to determine how these may affect pacing strategies.

This research provides clear evidence that playing bout duration effects physical performance in professional rugby union players. It was demonstrated that pacing strategies differ between backs and forwards regardless of bout type. Knowledge of these effects can be used to inform the planning of tactical substitutions for rugby union. 


\section{References}

Aughey, R.J. (2010). Australian football player work rate: Evidence of fatigue and pacing? International Journal of Sports Physiology and Performance, 5(3), 394-405.

Austin, D., Gabbett, T., \& Jenkins, D. (2011). The physical demands of Super 14 rugby union. Journal of Science and Medicine in Sport, 14(3), 259-63.

Baden, D.A., McLean, T., Tucker, R., (2005) Effect of anticipation during unknown or unexpected exercise duration on rating of perceived exertion, affect, and physiological function. British Journal of Sports Medicine, (39),742-6.

Bates, D., Maechler, M., Bolker, B., \& Walker, S. (2016) Package 'lme4', R package version 1.1-12

Black, G.M., \& Gabbett, T.J. (2014). Match intensity and pacing strategies in rugby league: An examination of whole-game and interchanged players, and winning and losing teams. Journal of Strength and Conditioning Research, 28(6), 1507-16.

Bradley, W.J., Morehen, J.C., Haigh, J., Clarke, J., Donovan, T.F., Twist, C., Cotton, C., Shepherd, S., Cocks, M., Sharma, A. and Impey, S.G. (2016) Muscle glycogen utilisation during Rugby match play: Effects of pre-game carbohydrate. Journal of Science and Medicine in Sport, 19(12), 1033-1038.

Bradley, P.S., \& Noakes, T.D. (2013). Match running performance fluctuations in elite soccer: Indicative of fatigue, pacing or situational influences? Journal of Sports Sciences, 31(15), 1627-38.

Carling, C., Espié, V., Le Gall, F., Bloomfield, J., \& Jullien, H. (2010). Work-rate of substitutes in elite soccer: A preliminary study. Journal of Science and Medicine in Sport, 13(2), 253-5.

Coutts, A.J., \& Duffield, R. (2010). Validity and reliability of GPS devices for measuring movement demands of team sports. Journal of Science and Medicine in Sport, 13(1), 133-5.

Cummins, C., Orr, R., O’Connor, H., \& West, C. (2013) Global positioning systems (GPS) and microtechnology sensors in team sports: a systematic review. Sports Medicine, 43(10), 1025-42

Cunniffe, B., Proctor, W., Baker, J.S. \& Davies, B., (2009) An evaluation of the physiological demands of elite rugby union using global positioning system 
tracking software. The Journal of Strength \& Conditioning Research, 23(4), 1195-1203.

Delaney, J.A., Cummins, C.J., Thornton, H.R. \& Duthie, G.M. Importance, Reliability, and Usefulness of Acceleration Measures in Team Sports. Journal of Strength and Conditioning Research, 32(12), 3485-93.

Duthie, G., Pyne, D., \& Hooper, S. (2003) Applied physiology and game analysis of rugby union. Sports Medicine, 33(13), 973-91

Edwards, A.M., \& Noakes, T.D. (2009). Dehydration: Cause of fatigue or sign of pacing in elite soccer? Sports Medicine, 39(1), 1-13.

Edwards A.M., Polman R.C.J. (2012) Pacing in sport and exercise: a psychophysiological perspective. New York: Nova Scientific Publishers.

Gabbett, T.J.(2013). Influence of the opposing team on the physical demands of elite rugby league match play. Journal of Strength and Conditioning Research, 27(6), 1629-35.

Gabbett, T.J. (2015). Influence of ball-in-play time on the activity profiles of rugby league match-play. Journal of Strength and Conditioning Research, 29(3), $716-21$

Gabbett, T.J., Walker, B., \& Walker, S. (2015). Influence of prior knowledge of exercise duration on pacing strategies during game-based activities.

International Journal of Sports Physiology and Performance, 10(3), 298-304.

Gréhaigne, J-F., \& Godbout, P. (2014). Dynamic systems theory and team sport coaching. Quest, 66(1), 96-116.

Higham, D.G., Pyne, D.B., Anson, J.M., \& Eddy, A. (2011). Movement patterns in rugby sevens: Effects of tournament level, fatigue and substitute players. Journal of Science and Medicine in Sport, 15(3), 277-82.

Highton, J., Mullen, T., \& Twist, C. (2017). Influence of knowledge of task endpoint on pacing and performance during simulated rugby league match play. International Journal of Sports Physiology and Performance, 12(9), 11921198.

Hills, S.P., Barrett, S., Feltbower, R.G., Barwood, M.J., Radcliffe, J.N., Cooke, C.B., Kilduff, L.P., Cook, C.J., \& Russell, M. (2019). A match-day analysis of the movement profiles of substitutes from a professional soccer club before and after pitch-entry. Plos One, 14(1): e0211563 
Hopkins, W.G., Marshall, S.W., Batterham, A.M., \& Hanin, J. (2009). Progressive statistics for studies in sports medicine and exercise science. Medicine and Science in Sports and Exercise, 41(1), 3-13.

Hulin, B.T., Gabbett, T.J., Kearney, S., \& Corvo, A. (2015) Physical demands of match play in successful and less-successful elite rugby league teams. International Journal of Sports Physiology and Preformance, 10(6), 703-710.

Johnston, R.D., Gabbett, T.J., \& Jenkins, D.G. (2014). Influence of number of contact efforts on running performance during game-based activities. International Journal of Sports Physiology and Performance, 10(6), 740-5.

Johnston, R.D., Gabbett, T.J., Seibold, A.J., \& Jenkins, D.G. (2014). Influence of physical contact on pacing strategies during game-based activities. International Journal of Sports Physiology and Performance, 9(5), 811-6.

Johnston, R.D., Weaving, D., Hulin, B.T., Till, K., Jones, B., and Duthie, G. (2019) Peak movement and collision demands of professional rugby league competition. International Journal of Sports Physiology and Performance [Epub ahead of print] doi: 10.13140/RG.2.2.36575.10405

Jones, M.R., West, D.J., Crewther, B.T., Cook, C.J. \& Kilduff, L.P. (2015) Quantifying positional and temporal movement patterns in professional rugby union using global positioning system. European Journal of Sport Science, $15(6), 1-9$

Kelly, S.J., Murphy, A.J., Watsford, M.L., Austin, D., \& Rennie, M. (2015). Reliability and validity of sports accelerometers during static and dynamic testing. International Journal of Sports Physiology and Performance, 10(1), 106-11.

Kempton, T., \& Coutts, A.J. (2015). Factors affecting exercise intensity in professional rugby league match-play. Journal of Science and Medicine in Sport, 19(6), 504-508.

Lacome, M., Piscione, J., Hager, J.P., \& Carling, C. (2016). Analysis of running and technical performance in substitute players in international male rugby union competition. International Journal of Sports Physiology and Performance. 11(6), 783-792

Lenth, R. (2019) Package 'emmeans', R package version 1.3.4 
Lindsay, A., Draper, N., Lewis, J., Gieseg, S. P., \& Gill, N. (2015). Positional demands of professional rugby. European Journal of Sport Science. 15(6), 480-487. doi:10.1080/17461391.2015.1025858

McLaren, S.J., Weston, M., Smith, A., Cramb, R., \& Portas, M.D. (2015) Variability of physical performance and player match loads in professional rugby union. Journal of Science and Medicine in Sport, 19(6), 493-7

McLellan, C.P., Lovell, D.I., \& Gass, G.C. (2011) Biochemical and endocrine responses to impact and collision during elite Rugby League match play. Journal of Strength and Conditioning Research, 25(6), 1553-62

McLellan, C.P., \& Lovell, D.I., (2012) Neuromuscular responses to impact and collision during elite rugby league match play. Journal of Strength and Conditioning Research, 26(5), 1431-30

Murray, A.M., \& Varley, M.C. (2015). Activity profile of international rugby sevens: Effect of score line, opponent, and substitutes. International Journal of Sports Physiology and Performance, 10(6), 791-801.

Orchard, J. (2012) More research is needed into the effects on injury of substitute and interchange rules in team sports. British Journal of Sports Medicine, 46(10), 694-5

Roberts, S.P., Trewartha, G., Higgitt, R.J., El-Abd, J., \& Stokes, K.A. (2008). The physical demands of elite English rugby union. Journal of Sports Sciences, 26(8), 825-33.

Sampson, J.A., Fullagar, H.H., \& Gabbett, T. (2015). Knowledge of bout duration influences pacing strategies during small-sided games. Journal of Sports Sciences, 33(1), 85-98.

Scott, D. \& Lovell, R. (2017) Individualisation of speed thresholds does not enhance the dose-response determination in football training. Journal of Sports Sciences, 36(13), 1523-32

St Clair Gibson, A., De Koning, J. J., Thompson, K. G., Roberts, W. O., Micklewright, D., Raglin, J., \& Foster, C. (2013). Crawling to the finish line: Why do endurance runners collapse? Implications for understanding of mechanisms underlying pacing and fatigue. Sports Medicine, 43, 413-424.

St Clair Gibson, A., \& Noakes, T.D. (2004) Evidence for complex system integration and dynamic neural regulation of skeletal muscle recruitment during exercise in humans. British Journal of Sports Medicine. 38, 797-806. 
St Clair-Gibson, A., Swart, J., \& Tucker, R. (2018) The interaction of psychological and physiological homeostatic drives and role of general control principles in the regulation of physiological systems, exercise and the fatigue process - The Integrative Governor theory. European Journal of Sport Science, 18(1), 25-36.

Tee, J.C., Ashford, A., \& Piggott, D. (2018). A tactical periodisation approach for rugby union. Strength and Conditioning Journal. [Epub ahead of print] doi:10.1519/SSC.0000000000000390

Tee, J.C., \& Coopoo, Y. (2015) Movement and impact characteristics of South African professional rugby union players. South African Journal of Sports Medicine, 27(2), 33-39

Tee, J.C., Lambert, M.I., \& Coopoo, Y. (2016). Impact of fatigue on positional movements during professional rugby union match play. International Journal of Sports Physiology and Performance, 12(4), 554-561.

Ulmer, H.V. (1996) Concept of an extracellular regulation of muscular metabolic rate during heavy exercise in humans by psychophysiological feedback. Experientia, 52(5), 416-20

Waldron, M., \& Highton, J. (2014). Fatigue and pacing in high-intensity intermittent team sport: An update. Sports Medicine, 44(12), 1645-58.

Waldron, M., Highton, J., Daniels, M., \& Twist, C. (2013). Preliminary evidence of transient fatigue and pacing during interchanges in rugby league. International Journal of Sports Physiology and Performance, 8(2), 157-64.

West, D.J., Finn, C., Cunningham, D.J., Shearer, D.A., Jones, M.R., Harrington, B., Crewther, B.T., Cook, C.J. \& Kilduff, L.P. (2013) The neuromuscular function, hormonal, and mood responses to a professional rugby union match. Journal of Strength and Conditioning Research, 28(1), 194-200 
1 Table 1 - Comparison of locomotive match performance variables according to participation bout type (whole game, starters and finishers) for

2 forward and back position groups.

\begin{tabular}{|c|c|c|c|c|c|c|}
\hline Forwards $(\mathrm{N}=51)$ & $\begin{array}{c}\text { Whole game } \\
(\mathrm{N}=19)\end{array}$ & $\begin{array}{c}\text { Starter } \\
(\mathrm{N}=16)\end{array}$ & $\begin{array}{c}\text { Finisher } \\
(\mathrm{N}=16)\end{array}$ & Whole game vs. Starter & Whole game vs. Finisher & Starter vs. Finisher \\
\hline $\begin{array}{l}\text { Time playing } \\
\text { (mins) }\end{array}$ & $96 \pm 12^{\#}$ & $61 \pm 11^{*}$ & $30 \pm 13^{* \#}$ & $\begin{array}{c}\text { Most likely very large } \\
(-3.03 \pm 1.03)\end{array}$ & $\begin{array}{c}\text { Most likely very large } \\
(-5.3 \pm 1.5)\end{array}$ & $\begin{array}{c}\text { Most likely very large } \\
(-2.59 \pm 0.95)\end{array}$ \\
\hline $\begin{array}{l}\text { Relative distance } \\
\left(\mathbf{m} \cdot \mathbf{m i n}^{-1}\right)\end{array}$ & $68 \pm 6$ & $66 \pm 6$ & $71 \pm 9$ & $\begin{array}{c}\text { Unclear } \\
(0.32 \pm 0.56)\end{array}$ & $\begin{array}{c}\text { Unclear } \\
(0.41 \pm 0.74)\end{array}$ & $\begin{array}{c}\text { Unclear } \\
(0.69 \pm 0.73)\end{array}$ \\
\hline $\begin{array}{l}\text { High speed distance } \\
\left(\mathrm{m} \cdot \mathrm{min}^{-1}\right)\end{array}$ & $10 \pm 4$ & $12 \pm 5$ & $17 \pm 9 * \#$ & $\begin{array}{c}\text { Unclear } \\
(0.45 \pm 0.66)\end{array}$ & $\begin{array}{l}\text { Very likely large } \\
\quad(1.47 \pm 0.95)\end{array}$ & $\begin{array}{l}\text { Very likely medium } \\
\quad(0.95 \pm 0.85)\end{array}$ \\
\hline $\begin{array}{l}\text { Acceleration frequency } \\
\text { (min per accel.) }\end{array}$ & $11 \pm 20$ & $10 \pm 21$ & $6 \pm 10^{* \#}$ & $\begin{array}{c}\text { Unclear } \\
(0.12 \pm 0.54)\end{array}$ & $\begin{array}{l}\text { Very likely large } \\
(1.39 \pm 0.88)\end{array}$ & $\begin{array}{l}\text { Very likely large } \\
\quad(1.32 \pm 0.92)\end{array}$ \\
\hline $\begin{array}{l}\text { Impact frequency } \\
\left(>5 G \cdot \text { min }^{-1}\right)\end{array}$ & $8.3 \pm 2.7$ & $11.3 \pm 2.5$ & $12.8 \pm 2.6$ & $\begin{array}{c}\text { Unclear } \\
(0.99 \pm 0.63)\end{array}$ & $\begin{array}{l}\text { Likely large } \\
(1.50 \pm 0.75)\end{array}$ & $\begin{array}{l}\text { Likely small } \\
(0.55 \pm 0.82)\end{array}$ \\
\hline Backs $(\mathrm{N}=49)$ & $\begin{array}{c}\text { Whole game } \\
(\mathrm{N}=27)\end{array}$ & $\begin{array}{l}\text { Starter } \\
(\mathrm{N}=19)\end{array}$ & $\begin{array}{c}\text { Finisher } \\
(\mathbf{N}=3)\end{array}$ & Whole game vs. Starter & Whole game vs. Finisher & Starter vs. Finisher \\
\hline $\begin{array}{l}\text { Time playing } \\
\text { (mins) }\end{array}$ & $96 \pm 8^{\#}$ & $61 \pm 14 *$ & $24 \pm 9 * \#$ & $\begin{array}{c}\text { Most likely very large } \\
(-3.22 \pm 0.93)\end{array}$ & $\begin{array}{c}\text { Most likely very large } \\
(-8.55 \pm 1.96)\end{array}$ & $\begin{array}{c}\text { Most likely very large } \\
(-2.55 \pm 0.99)\end{array}$ \\
\hline $\begin{array}{l}\text { Relative distance } \\
\left(\mathbf{m} \cdot \mathbf{m i n}^{-1}\right)\end{array}$ & $65 \pm 4$ & $71 \pm 8$ & $65 \pm 15$ & $\begin{array}{l}\text { Likely medium } \\
(1.01 \pm 0.60)\end{array}$ & $\begin{array}{c}\text { Unclear } \\
(0.02 \pm 0.59)\end{array}$ & $\begin{array}{c}\text { Unclear } \\
(-0.53 \pm 0.61)\end{array}$ \\
\hline $\begin{array}{l}\text { High speed distance } \\
\left(\mathrm{m} \cdot \mathrm{min}^{-1}\right)\end{array}$ & $12 \pm 3$ & $16 \pm 5$ & $16 \pm 2$ & $\begin{array}{l}\text { Likely medium } \\
(1.01 \pm 0.60)\end{array}$ & $\begin{array}{c}\text { Unclear } \\
(1.44 \pm 1.35)\end{array}$ & $\begin{array}{c}\text { Unclear } \\
(0.05 \pm 0.59)\end{array}$ \\
\hline $\begin{array}{l}\text { Acceleration frequency } \\
\text { (min per accel.) }\end{array}$ & $5 \pm 10$ & $5 \pm 9$ & $4 \pm 6$ & $\begin{array}{c}\text { Unclear } \\
(0.24 \pm 0.52)\end{array}$ & $\begin{array}{c}\text { Unclear } \\
(0.78 \pm 3.05)\end{array}$ & $\begin{array}{c}\text { Unclear } \\
(0.48 \pm 2.77)\end{array}$ \\
\hline $\begin{array}{l}\text { Impact frequency }(>5 \\
\left.G \cdot \min ^{-1}\right)\end{array}$ & $9.5 \pm 3.1$ & $9.6 \pm 3.1$ & $9.1 \pm 6.4$ & $\begin{array}{c}\text { Unclear } \\
(0.03 \pm 0.59)\end{array}$ & $\begin{array}{c}\text { Unclear } \\
(-0.14 \pm 3.38)\end{array}$ & $\begin{array}{c}\text { Unclear } \\
(-0.16 \pm 3.33)\end{array}$ \\
\hline
\end{tabular}

Note: Data presented as mean $\pm S D$. Role indicates whether a player completed the whole game (whole), started the game and was substituted (starter) or did not start the game and came on as a substitute (finisher). Acceleration frequency indicates how regularly players exceeded the acceleration threshold of $2.75 \mathrm{~m} \bullet \mathrm{s}^{-1}$. Impact frequency indicates the number of time that player collision-forces exceeded 5G. *\# indicates significant difference from whole game and starters respectively $(P<0.05)$. Paired comparisons are a statement of the likelihood and magnitude of effects $($ Effect size $\pm 95 \% \mathrm{CI})$. Likelihood for substantial effects are described as possibly (25-75\%), likely (75-95\%), very likely (95-99.5\%) and most likely (>99.5\%). 
8 Table 2 - Temporal differences in locomotive movement patterns throughout match play quartiles for players who complete a whole game,

9 players who start a game and are replaced (starters) and players who come on as substitutes (finishers).

\begin{tabular}{|c|c|c|c|c|c|c|c|c|c|}
\hline \multirow{5}{*}{$\begin{array}{l}\text { Relative distance } \\
\left(\mathbf{m} \cdot \mathbf{m i n}^{-1}\right)\end{array}$} & \multirow{3}{*}{$\begin{array}{l}\text { Role } \\
\text { Whole }\end{array}$} & \multicolumn{4}{|c|}{ Forwards } & \multicolumn{4}{|c|}{ Backs } \\
\hline & & Q1 & Q2 & Q3 & Q4 & Q1 & Q2 & Q3 & Q4 \\
\hline & & $73 \pm 8$ & $70 \pm 15$ & $65 \pm 7$ & $67 \pm 10$ & $67 \pm 8$ & $67 \pm 8$ & $66 \pm 5$ & $61 \pm 7$ \\
\hline & Starter & $73 \pm 9$ & $66 \pm 7^{\S}$ & $64 \pm 14^{\#}$ & $67 \pm 10$ & $72 \pm 11$ & $70 \pm 9$ & $72 \pm 13$ & $70 \pm 11$ \\
\hline & Finisher & $72 \pm 12$ & $75 \pm 12$ & $65 \pm 15$ & $71 \pm 17$ & $58 \pm 19$ & $54 \pm 19$ & $62 \pm 26$ & $87 \pm 27$ \\
\hline Whole vs. Starter & & Most likely trivial & $\begin{array}{l}\text { Likely small } \\
(0.3 \pm 0.5)\end{array}$ & Unclear & Most likely trivial & Unclear & Unclear & Unclear & Unclear \\
\hline Whole vs. Finisher & & Most likely trivial & Unclear & $\begin{array}{l}\text { Most likely } \\
\text { trivial }\end{array}$ & Unclear & Unclear & Unclear & Unclear & Unclear \\
\hline Starter vs. Finisher & & Possibly trivial & $\begin{array}{l}\text { Likely medium } \square \\
\quad(0.9 \pm 0.5)\end{array}$ & Unclear & Unclear & Unclear & Unclear & Unclear & Unclear \\
\hline High speed distance & Whole & $12 \pm 6$ & $10 \pm 7$ & $9 \pm 4^{\#}$ & $9 \pm 5^{\#}$ & $13 \pm 5$ & $13 \pm 5$ & $12 \pm 3$ & $11 \pm 3$ \\
\hline$\left(\mathbf{m} \cdot \min ^{-1}\right)$ & Starter & $16 \pm 6$ & $11 \pm 7^{\#}$ & $10 \pm 6^{\#}$ & $10 \pm 7^{\#}$ & $17 \pm 7$ & $16 \pm 6$ & $17 \pm 7$ & $14 \pm 7$ \\
\hline & Finisher & $19 \pm 12$ & $17 \pm 12$ & $14 \pm 12^{\#}$ & $16 \pm 10^{\#, \S}$ & $15 \pm 5$ & $11 \pm 9$ & $15 \pm 14$ & $23 \pm 18$ \\
\hline Whole vs. Starter & & Unclear & Unclear & Unclear & Unclear & Unclear & Unclear & Unclear & Unclear \\
\hline Whole vs. Finisher & & Unclear & $\begin{array}{l}\text { Likely medium } \square \\
\quad(0.7 \pm 0.7)\end{array}$ & Unclear & $\begin{array}{l}\text { Likely medium } \\
\quad(0.8 \pm 0.5)\end{array}$ & Unclear & Unclear & Unclear & Unclear \\
\hline Starter vs. Finisher & & Unclear & $\begin{array}{l}\text { Likely small } \square \\
(0.5 \pm 0.6) \square\end{array}$ & $\begin{array}{l}\text { Likely small } \\
(0.5 \pm 0.6)\end{array}$ & $\begin{array}{l}\text { Likely medium } \\
\quad(0.7 \pm 0.6)\end{array}$ & Unclear & Unclear & Unclear & Unclear \\
\hline Acceleration & Whole & $8 \pm 11$ & $14 \pm 20^{\#}$ & $14 \pm 20^{\#}$ & $13 \pm 13^{\#}$ & $5 \pm 8$ & $5 \pm 8$ & $5 \pm 9$ & $6 \pm 8$ \\
\hline frequency & Starter & $10 \pm 12$ & $11 \pm 14$ & $9 \pm 13$ & $13 \pm 14$ & $4 \pm 6$ & $4 \pm 5$ & $4 \pm 5$ & $4 \pm 8$ \\
\hline (min per accel.) & Finisher & $5 \pm 5^{\&}$ & $6 \pm 5$ & $7 \pm 6$ & $8 \pm 7$ & $3 \pm 3$ & $4 \pm 5$ & $4 \pm 5$ & $4 \pm 8$ \\
\hline Whole vs. Starter & & Unclear & Unclear & Unclear & Unclear & Unclear & Unclear & Unclear & Unclear \\
\hline Whole vs. Finisher & & Possibly trivial & $\begin{array}{l}\text { Likely small } \\
(0.5 \pm 0.6)\end{array}$ & $\begin{array}{l}\text { Possibly small } \\
\quad(0.6 \pm 0.7)\end{array}$ & Unclear & Unclear & Unclear & Unclear & Unclear \\
\hline Starter vs. Finisher & & $\begin{array}{l}\text { Possibly medium } \\
\quad(0.7 \pm 0.6)\end{array}$ & $\begin{array}{l}\text { Possibly small } \\
(0.5 \pm 0.6)\end{array}$ & Unclear & Unclear & Unclear & Unclear & Unclear & Unclear \\
\hline Impact frequency & Whole & $11 \pm 5$ & $8 \pm 2$ & $8 \pm 4$ & $8 \pm 3$ & $10 \pm 4$ & $10 \pm 4$ & $10 \pm 3$ & $9 \pm 3$ \\
\hline$\left(>5 \mathrm{G} \cdot \mathrm{min}^{-1}\right)$ & Starter & $14 \pm 4$ & $10 \pm 2$ & $10 \pm 4$ & $11 \pm 4$ & $10 \pm 4$ & $10 \pm 4$ & $10 \pm 4$ & $9 \pm 3$ \\
\hline Whole vs. Starter & Finisher & $\begin{array}{l}14 \pm 6^{\S} \\
\text { Unclear }\end{array}$ & $\begin{array}{c}14 \pm 4^{\S, \&} \\
\text { Unclear }\end{array}$ & $\begin{array}{l}10 \pm 5^{\S} \\
\text { Unclear }\end{array}$ & $\begin{array}{c}13 \pm 5^{\S, \&} \\
\text { Unclear }\end{array}$ & $\begin{array}{c}12 \pm 7 \\
\text { Most likely } \\
\text { trivial }\end{array}$ & $\begin{array}{c}7 \pm 6 \\
\text { Most likely } \\
\text { trivial }\end{array}$ & $\begin{array}{c}4 \pm 4 \\
\text { Most likely trivial }\end{array}$ & $\begin{array}{c}13 \pm 12 \\
\text { Most likely trivial }\end{array}$ \\
\hline Whole vs. Finisher & & $\begin{array}{l}\text { Very likely } \\
\text { medium } \\
(0.6 \pm 0.5)\end{array}$ & $\begin{array}{l}\text { Most likely large } \\
\quad(1.6 \pm 0.6)\end{array}$ & $\begin{array}{l}\text { Likely small } \\
(0.4 \pm 0.5)\end{array}$ & $\begin{array}{l}\text { Very likely medium } \\
\quad(1.0 \pm 0.6)\end{array}$ & Unclear & Unclear & Unclear & Unclear \\
\hline
\end{tabular}


Note: Data presented as mean \pm SD. Role indicates whether a player completed the whole game (whole), started the game and was substituted (starter) or did not start the game and came on as a substitute (finisher). Q1-4 indicate quartiles of the playing duration for each role. Acceleration frequency indicates how regularly players exceeded the acceleration threshold of $2.75 \mathrm{~m} \bullet \mathrm{s}^{-1}$. Impact frequency indicates the number of time that player collision-forces exceeded 5G. \# indicates significant main effect of time where the period indicated is significantly different from Q1. ${ }^{\&}$ indicates significant main effects of bout where the group indicated is significantly different from whole game players or starters respectively. Paired comparisons are a statement of the likelihood and magnitude of effects (Effect size $\pm 95 \% \mathrm{CI}$ ). Likelihood for substantial effects are described as possibly (25-75\%), likely (75-95\%), very likely $(95-99.5 \%)$ and most likely $(>99.5 \%)$. 
Table 3 - Differences in movement variables between the last quartile played by players who complete the whole game, or started the game and were substituted (starters), and the four quartiles completed by players who came on as substitutes (finishers).

\begin{tabular}{|c|c|c|c|c|c|}
\hline & & \multicolumn{4}{|c|}{ Substitute Players } \\
\hline & & Q1 & $\mathrm{Q} 2$ & Q3 & Q4 \\
\hline \multirow{2}{*}{$\begin{array}{l}\text { Relative distance } \\
\left(\mathbf{m} \cdot \mathbf{m i n}^{-1}\right)\end{array}$} & Whole vs. Finisher & $\begin{array}{l}\text { Likely small } \\
(0.5 \pm 0.6)\end{array}$ & $\begin{array}{l}\text { Very likely medium } \\
(0.8 \pm 0.6)^{*}\end{array}$ & Unclear & Unclear \\
\hline & Starter vs. Finisher & $\begin{array}{l}\text { Likely medium } \\
(0.6 \pm 0.6)\end{array}$ & $\begin{array}{l}\text { Very likely medium } \\
(0.9 \pm 0.6)^{*}\end{array}$ & Unclear & Unclear \\
\hline \multirow[t]{2}{*}{$\begin{array}{l}\text { High speed distance } \\
\left(\mathrm{m} \cdot \mathrm{min}^{-1}\right)\end{array}$} & Whole vs. Finisher & $\begin{array}{l}\text { Very likely medium } \\
(1.0 \pm 0.6)^{*}\end{array}$ & $\begin{array}{l}\text { Very likely medium } \\
(0.8 \pm 0.6)^{*}\end{array}$ & $\begin{array}{l}\text { Likely small } \\
(0.5 \pm 0.6)\end{array}$ & $\begin{array}{l}\text { Very likely medium } \\
(0.8 \pm 0.6)^{*}\end{array}$ \\
\hline & Starter vs. Finisher & $\begin{array}{l}\text { Very likely medium } \\
(0.9 \pm 0.6)^{*}\end{array}$ & $\begin{array}{l}\text { Likely medium } \\
(0.7 \pm 0.6)^{*}\end{array}$ & $\begin{array}{l}\text { Likely small } \\
(0.5+0.6)\end{array}$ & $\begin{array}{l}\text { Likely medium } \\
(0.7 \pm 0.6)^{*}\end{array}$ \\
\hline \multirow{2}{*}{$\begin{array}{l}\text { Acceleration } \\
\text { frequency } \\
\text { (min per accel.) }\end{array}$} & Whole vs. Finisher & $\begin{array}{l}\text { Likely medium } \\
(0.9 \pm 0.6)^{*}\end{array}$ & $\begin{array}{l}\text { Likely small } \\
(0.5 \pm 0.6)\end{array}$ & $\begin{array}{l}\text { Likely small } \\
(0.5 \pm 0.6)\end{array}$ & Unclear \\
\hline & Starter vs. Finisher & $\begin{array}{l}\text { Very likely medium } \\
(0.9 \pm 0.6)^{*}\end{array}$ & $\begin{array}{l}\text { Likely small } \\
(0.6 \pm 0.6)\end{array}$ & $\begin{array}{l}\text { Likely small } \\
(0.5 \pm 0.6)\end{array}$ & Unclear \\
\hline \multirow[t]{2}{*}{$\begin{array}{l}\text { Impacts frequency } \\
\left(>5 \mathrm{G} \cdot \mathrm{min}^{-1}\right)\end{array}$} & Whole vs. Finisher & $\begin{array}{l}\text { Very likely large } \\
(1.2 \pm 0.8)^{*}\end{array}$ & $\begin{array}{l}\text { Very likely large } \\
(1.3 \pm 0.8)^{*}\end{array}$ & Unclear & $\begin{array}{l}\text { Likely medium } \\
(1.0 \pm 0.8)\end{array}$ \\
\hline & Starter vs. Finisher & $\begin{array}{l}\text { Likely medium } \\
(0.7 \pm 0.9)\end{array}$ & $\begin{array}{l}\text { Likely medium } \\
(0.7 \pm 0.8)\end{array}$ & Unclear & Unclear \\
\hline
\end{tabular}

Note: Whole indicates that a player completed the whole game, Starter indicates that a player started the game and was substituted, Finisher indicates that a player did not start the game and come on as a substitute. Q1-4 indicate quartiles of the playing duration for substitute players. Acceleration frequency indicates how regularly players exceeded the acceleration threshold of $2.75 \mathrm{~m} \cdot \mathrm{s}^{-1}$. Paired comparisons are a statement of the likelihood and magnitude of effects (Effect size $\pm 95 \%$ CI). Likelihood for substantial effects are described as possibly (25-75\%), likely (75-95\%), very likely (95-99.5\%) and almost certain $(>99.5 \%)$. * indicates significant differences from finishers in the period indicated 


\section{Figures}

Forwards
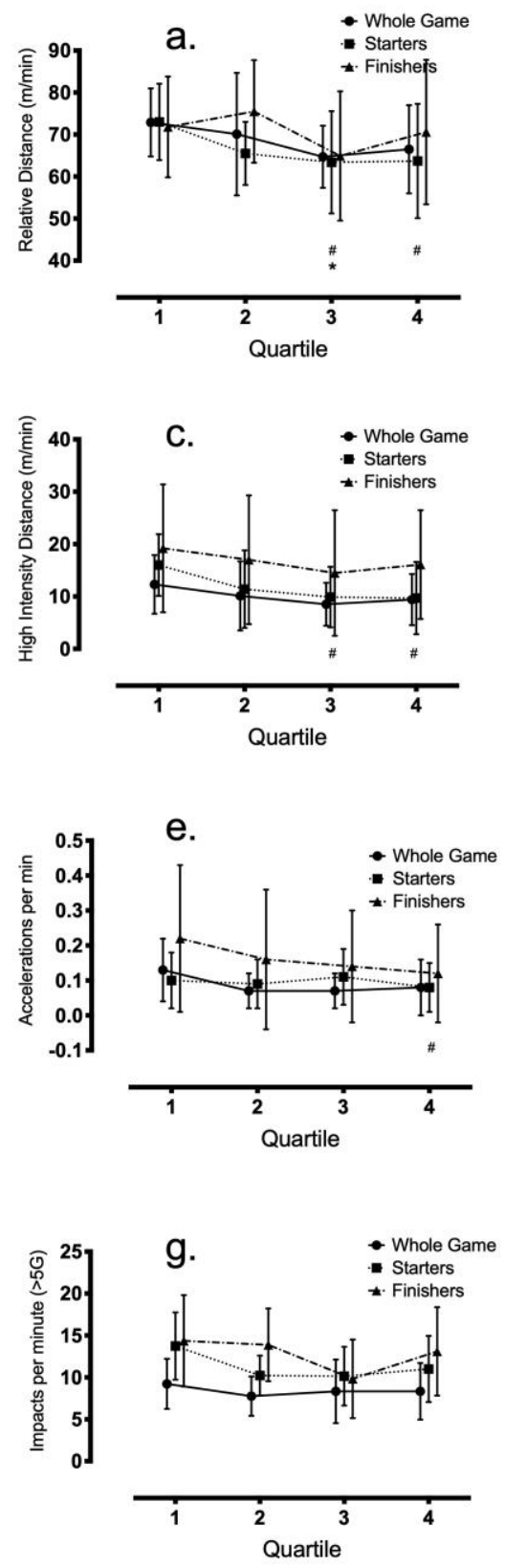

Backs

b.

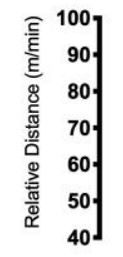

o. Whole Game
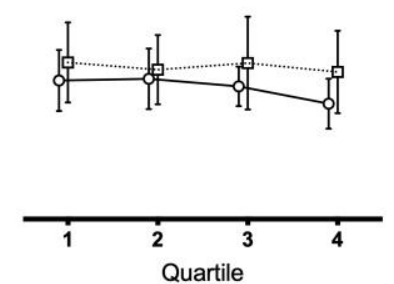

d.

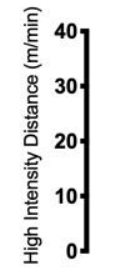

o. Whole Game
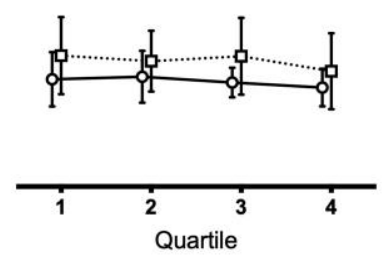

$f$.

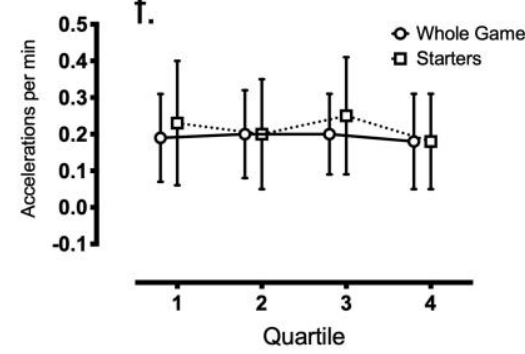

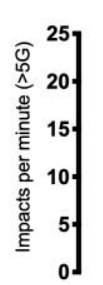

h. OWhole Game Q Starters

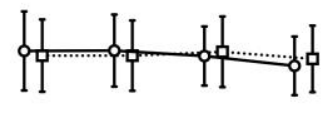

Figure 1 - Relative total distance (a,b), high-speed distance (c,d) acceleration frequency $(\mathrm{e}, \mathrm{f})$ and impact frequency (g,h) of forwards and backs, differentiated by bout type (whole, starter or finisher) in each quartile of professional rugby union matches. *, \# indicates significant effect of time where the period indicated is significantly different from Q1 or Q2 respectively. 

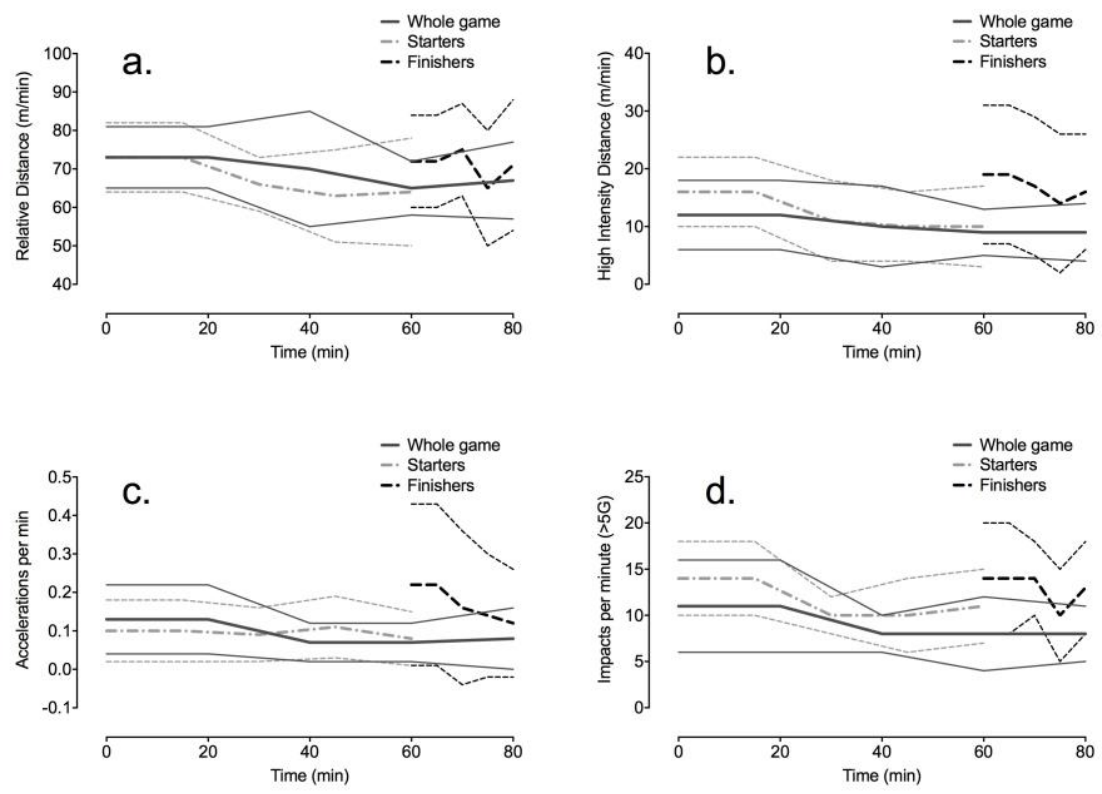

Figure 2 - Time series depiction of mean locomotive variables (a. relative distance, $b$. high-speed distance, c. acceleration frequency, d. impact frequency) for different bout types. Solid lines and error bars are mean and standard deviation for whole game players, dashed lines and error bars represent the same for starters and finishers 